\title{
A importância dos inventários do programa GHG Protocol para a gestão das emissões ambientais: estudo de caso do Maranhão
}

Estudos acadêmicos correlatos demonstram a importância da divulgação de inventários ou relatórios com informações ambientais e despertam para a questão da qualidade dessas informações com relação à robustez e credibilidade do relatório. Assim, este trabalho tem como objetivo examinar os perfis dos inventários de emissões de GEE do registro público do Programa GHG Protocol elaborados pelas empresas localizadas no Maranhão, e avalia a significância desses documentos em prestar informações claras sobre a eficácia das ações ambientais frente ao quadro das mudanças climáticas. Para tanto, este se baseia numa abordagem qualitativa, com o emprego de pesquisa do tipo descritiva e a utilização de procedimentos bibliográfico e documental, por meio de análise de conteúdo de dados secundários. A análise das evidências foi desenvolvida com base nas informações contidas nos inventários de emissões disponibilizados pelo programa GHG Protocol das empresas notadas por A, B, C, D, E, F e G juntamente com outras informações de seus desempenhos ambientais disponíveis nos sites das empresas analisadas. $O$ resultado do estudo indica que os inventários avaliados não apresentaram uma análise crítica, bem como foram identificadas oportunidades de melhoria na clareza das ações que estão ou foram implantadas para a redução dos GEE, na divulgação dos inventários e na efetivação da ferramenta como instrumento de gestão das emissões.

Palavras-chave: Importância; Inventários de emissões; Programa GHG Protocol; Gestão de Emissões Atmosféricas.

\section{The importance of GHG Protocol program inventories for the management of environmental emissions: case study from Maranhão}

\begin{abstract}
Related academic studies demonstrate the importance of disclosing inventories or reports with environmental information and raise the issue of the quality of this information in relation to the robustness and credibility of the report. Thus, this paper aims to examine the GHG Protocol profiles of GHG Protocol public registry inventories prepared by companies located in Maranhão, and evaluates the significance of these documents in providing clear information on the effectiveness of environmental actions against the framework of climate changes. Therefore, it is based on a qualitative approach, with the use of descriptive research and the use of bibliographic and documentary procedures, through content analysis of secondary data. Evidence analysis was developed based on the information contained in the GHG Protocol emissions inventory of companies noted by $A, B, C, D, E, F$ and $G$ along with other information on their environmental performance available on company websites. analyzed. The result of the study indicates that the inventories evaluated did not present a critical analysis, as well as opportunities for improvement in the clarity of the actions that are or have been implemented to reduce GHG, the disclosure of inventories and the effectiveness of the tool as a management tool. of emissions.
\end{abstract}

Keywords: Importance; Emission inventories; GHG Protocol Program; Air Emissions Management.

Topic: Desenvolvimento, Sustentabilidade e Meio Ambiente

Reviewed anonymously in the process of blind peer.
Received: 12/07/2018

Approved: $17 / 10 / 2018$
Vanessa Silva Melo

Universidade Federal do Maranhão, Brasil

http://lattes.cnpq.br/4574760305337321

http://orcid.org/0000-0002-0007-8241

vanessa1886@hotmail.com

Francisco Sávio Mendes Sinfrônio (ib

Universidade Federal do Maranhão, Brasil

http://lattes.cnpq.br/5984945942545807

http://orcid.org/0000-0003-0388-7586

kjvida@mac.com
Referencing this:

MELO, V. S.; SINFRÔNIO, F. S. M.. A importância dos inventários do programa GHG Protocol para a gestão das emissões ambientais: estudo de caso do Maranhão. Natural Resources, v.8, n.2, p.38-51, 2018. DOI: http://doi.org/10.6008/CBPC2237-9290.2018.002.0005 


\section{INTRODUÇÃO}

As emissões de gases de efeito estufa, tendo como consequência o aumento da temperatura global, vêm, cada vez mais, despertando a atenção da sociedade, resultando em uma crescente demanda do mercado por informações sobre a mensuração dos riscos climáticos, bem como das ações de mitigação e de adaptação para uma economia de baixo carbono.

Segundo a Política Nacional de Mudanças Climáticas, regulamentada pela Lei n.12187, de 29 de dezembro de 2009, o efeito estufa pode ser descrito como "Constituintes gasosos, naturais ou antrópicos, que, na atmosfera, absorvem e reemitem radiação infravermelha" (BRASIL, 2009). Vale observar que tal mecanismo expressa função essencial para a vida na terra, pois em escala controlada, há a responsabilidade pela manutenção da temperatura do planeta. Já o chamado aquecimento global, por outro lado, é um fenômeno associado ao aumento da temperatura devido ao descontrole das emissões de gases de efeito estufa, decorrentes das atividades humanas. A globalização dos problemas ambientais correlacionados ao clima é um fato evidente, e as empresas estão, desde sua origem, no centro desse processo (BARBIERI, 2016).

Dentre os gases de efeito estufa (GEE) são englobados: dióxido de carbono $\left(\mathrm{CO}_{2}\right)$, metano $\left(\mathrm{CH}_{4}\right)$, óxido nitroso $\left(\mathrm{N}_{2} \mathrm{O}\right)$, os perfluorcarbonos $(\mathrm{PFC})$, os hidrofluorcarbonos $(\mathrm{HFC})$, trifluoreto de nitrogênio $\left(\mathrm{NF}_{3}\right)$ e o hexafluoreto de enxofre $\mathrm{SF}_{6}$, sendo, portanto, grandes responsáveis pelas alterações climáticas. Diante desse cenário, são necessárias ações para o controle das emissões atmosféricas baseadas em metodologias que estabeleçam uma gestão eficiente na quantidade de poluentes lançados no ambiente.

Como país signatário da Convenção-Quadro das Nações Unidas sobre Mudança do Clima (UNFCCC), doravante referenciada como Convenção, o Brasil tem como suas principais obrigações a elaboração e a atualização periódica do Inventário Nacional de Emissões de Gases de Efeito Estufa não Controlados pelo Protocolo de Montreal, referenciado como Inventário ${ }^{1}$.

O Ministério da Ciência, Tecnologia, Inovações e Comunicações (MCTIC) tem elaborado inventários nacionais prevendo Estimativas Anuais de Emissões de Gases de Efeito Estufa (GEE) no Brasil. Esse documento tem por objetivo acompanhar o desempenho do compromisso nacional voluntário assumido pelo Brasil para a redução das emissões de gases de efeito estufa até o ano de 2020. Em sua 3o edição, observa-se uma evolução da metodologia de cálculo na projeção de emissões ao longo do tempo com a apresentação de detalhamentos em termos dos setores e subsetores, além das unidades federativas (BRASIL, 2016a).

Desse modo, o Programa Brasileiro The Greenhouse Gas Protocol (GHG Protocol - O Protocolo de gases de efeito estufa) busca promover a cultura corporativa de mensuração, publicação e gestão voluntária das emanações de GEE no Brasil. Essas ações proporcionam aos participantes acesso a instrumentos e padrões de qualidade internacional para contabilização e elaboração de inventários de GEE.

Assim, o Programa Brasileiro GHG Protocol, em consonância com as normas da ISO e com as metodologias do IPCC (Painel Intergovernamental sobre Mudança Climáticas), tem sido a metodologia mais 
utilizada pelas corporações para fazer esse diagnóstico. Saliente-se que, no caso especifico do estado do Maranhão, algumas empresas de grande porte no ramo da mineração, construção civil, metalurgia, indústrias extrativas e indústria de transformação, declaram seus registros de emissões presentes em seus processos, porém nem todas as empresas se mantêm continuamente no programa existindo, portanto, uma sazonalidade na informação dos dados.

Sendo assim, referente à efetivação de ações para redução dessas liberações na atmosfera, o presente estudo tem como objetivo avaliar a abrangência dos inventários públicos do Programa GHG Protocol, bem como as ações decorrentes desses relatórios anuais realizados de forma voluntária por empresas localizadas no Maranhão.

\section{REVISÃO TEÓRICA}

\section{Legislação Ambiental}

À Política Nacional sobre Mudanças do Clima (PNMC), introduziu-se a previsão de utilização de instrumentos financeiros e econômicos para promover ações de mitigação e adaptação às mudanças do clima. De acordo com Política de dezembro de 2009, em seu Art. 6으, XIII, os instrumentos são apresentados sob a forma de registros, inventários, estimativas, avaliações e quaisquer outros estudos de emissões de gases de efeito estufa e de suas fontes, elaborados com base em informações e dados fornecidos por entidades públicas e privadas (BRASIL, 2009).

Tais orientações se fazem presentes no inventário de GEE, o qual tem sido adotado por estados brasileiros como Minas Gerais (2009), São Paulo (2009) e Rio de Janeiro (2010), (Decreto Estadual 45.229/2009, Lei no 13.798/2009 e Lei no 5.690/2010, respectivamente). As demais localidades, a exemplo do Maranhão, ainda não possuem lei específica para elaboração de inventários.

Nesse interim, o IE (2012) explica que, embora de forma geral, todos os estados apontem para a realização de inventários das suas emissões, eles diferem na especificação da periodicidade e na definição de referência sobre o seu escopo. $O$ documento explica, ainda, que as regras dos Protocolos para a efetivação de tais documentos precisam ser definidas e demandam um denominador comum, ou seja, mesmo que não utilizem metodologias iguais, eles precisam ser harmonizados, estendendo isso também para verificação e validação.

Vale ressaltar, a Conferência das Partes (COP-21), em dezembro de 2015, na França, que reuniu chefes de Estado de todo o mundo. Nessa Conferência Mundial sobre o Clima, foi assinado o acordo no qual os 195 países signatários firmaram o compromisso de atuarem para que a temperatura média do planeta não sofra uma variação acima de $2^{\circ} \mathrm{C}$. Outro ponto muito importante da Conferência foi a utilização de inventários de emissões como o principal instrumento de apoio à redução das emissões (COP-21, 2015).

A COP-22, realizada em novembro de 2016, na cidade de Marrakesh (Marrocos), representou um 'ponto de partida', com foco na definição do chamado 'livro de regras', que estabelece como será a implementação das obrigações assumidas em Paris para a redução de gases poluentes (COP-22, 2016). A última Conferência das Partes (COP-23) ocorreu em novembro de 2017, na cidade de Bonn, Alemanha, teve 
a missão de avançar no desenho do livro de regras do Acordo de Paris. É a primeira COP presidida por uma nação insular do Pacífico, Fiji, cuja própria existência é ameaçada pelo aumento do nível do mar em decorrência do aquecimento global (COP-23, 2017).

Outrossim, é importante lembrar a respeito da história do clima brasileiro, da Primeira Comunicação Nacional do Brasil, preparada de acordo com o Painel Intergovernamental sobre Mudança Climática (IPCC), que foi lançada em 2004, na 10 Conferência das Partes da CQNUMC, em Buenos Aires. O documento continha o primeiro inventário de emissão de GEE do Brasil, que abrangeu o período de 1990-1994 (BRASIL, 2004). Já a Segunda Comunicação Nacional, lançada em 2010, atualizou os resultados de 1990-1994 e apresentou os registros do período entre 2000-2005 (BRASIL, 2010).

Recentemente, a Terceira Comunicação Nacional, publicada em 2016, reforça o compromisso do País, como integrante da Convenção, de elaborar, atualizar e prover à Conferência das Partes inventários nacionais de emissões antrópicas por fontes e remoções por sumidouros de todos os gases de efeito estufa (GEE) não controlados pelo Protocolo de Montreal. O documento compreende o Inventário referente ao período de 1990 a 2010 (BRASIL, 2016b).

\section{Programa GHG Protocol}

O Greenhouse Gas Protocol (GHG Protocol) é uma iniciativa que teve desenvolvimento originário nos Estados Unidos em 1998, ocasião em que foram reunidos membros da academia, governos e organizações não governamentais, sob a coordenação do World Business Council for Sustenable Development (WBCSD) e do World Resources Institute (WRI). A partir daí, o GHG Protocol passou a ter como objetivo desenvolver padrões e inventários que retratem o quadro das organizações, sendo uma ferramenta utilizada para entender, quantificar e gerenciar as liberações de GEE. Então, atualmente, este, é um dos métodos mais utilizado, no âmbito mundial, pelas empresas e governos para a realização desses inventários.

O Programa se propõe a constituir a plataforma nacional para publicação de tais listagens corporativas e organizacionais. Desse modo, sua implementação é uma iniciativa do Centro de Estudos em Sustentabilidade, da Fundação Getúlio Vargas (FGV), e do World Resources Institute (WRI), em parceria com o Ministério do Meio Ambiente (MMA), o Conselho Empresarial Brasileiro para o Desenvolvimento Sustentável (CEBDS) e o World Business Council for Sustainable Development (WBCSD).

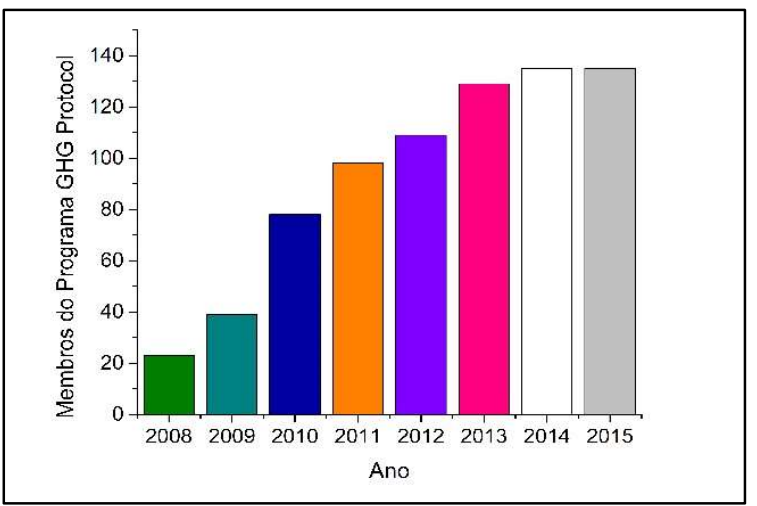

Figura 1: Quantitativo de Membros do Programa GHG Protocol. Fonte: FGV (2017). 
Do mesmo modo, a plataforma GHG Protocol também desenvolve e disponibiliza ferramentas computacionais que auxiliam no processo de contabilização de emissões corporativas de GEE, atuando como instrumento de apoio para a gestão dessas liberações. No entanto, embora o programa seja deveras importante, nota-se que o número de empresas-membro ainda é pouco expressivo diante do contingente de instituições no Brasil. Ressalve-se que, ainda assim, é possível observar um crescimento no número de organizações que aderiram ao programa desde 2008, conforme se pode notar na figura 1.

Conforme é possível ver na figura, de acordo com o Registro Público de Emissões FGV (2017), 200 organizações já publicaram inventários de GEE, utilizando a metodologia disponibilizada pelo programa. Desse total, 27 empresas são consideradas fundadoras. Não obstante, nos relatórios de 2015, foram 137 companhias que declaram 401 milhões de toneladas de $\mathrm{CO}_{2} \mathrm{e}$, o que representa somente $9 \%$ da emissão do Brasil. Dessas 137 corporações, 87 estão no estado de São Paulo e inseridas em 18 setores econômicos. 0 maior grupo, e maior emissor, é o das indústrias de transformação (48), seguida pelo setor financeiro e de seguros (16 organizações) e, por último, eletricidade e gás (12 empresas) (FGV, 2017).

De acordo com o WRI, para a elaboração de inventários corporativos, cinco passos básicos devem ser seguidos a fim de que os objetivos sejam alcançados: definição dos limites operacionais e organizacionais do inventário; coleta de dados das atividades que resultam na emissão de GEE; cálculo das emissões; adoção de estratégias de gestão, como o aumento de eficiência, projetos para créditos de carbono, introdução de novas linhas de produtos, mudança de fornecedor, entre outros, e apresentação dos resultados. Assim, segundo o Centro de estudos em Sustentabilidade da Fundação Getúlio Vargas, a elaboração do rol de emissões de GEE é considerada o primeiro passo para que uma instituição ou empresa contribua com a prevenção de mudanças do clima.

De tal maneira, entende-se que o programa em análise atende aos requisitos do Protocolo de Kyoto e, portanto, devem ser incluídos ao inventário de emissões todos os gases internacionalmente reconhecidos como GEE, a saber: dióxido de carbono $\left(\mathrm{CO}_{2}\right)$, metano $\left(\mathrm{CH}_{4}\right)$, óxido nitroso $\left(\mathrm{N}_{2} \mathrm{O}\right)$, hexafluoreto de enxofre $\left(\mathrm{SF}_{6}\right)$, hidrofluorcarbono (HFC), perfluorcarbonos (PFC), clorofluorcarbono (CFC).

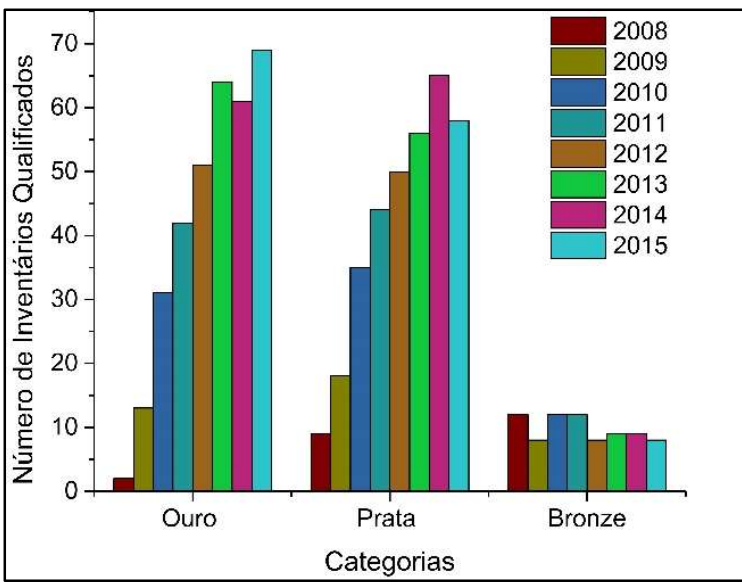

Figura 2: Número de Inventários por qualificação (ouro, prata e bronze) disponíveis no Programa GHG Protocol Brasil. Fonte: FGV (2016)

O Programa Brasileiro desenvolveu um sistema de qualificação para inventários de emissões, nas quais são adotadas as denominações, Bronze, Prata ou Ouro, de acordo com a abrangência e o controle no 
monitoramento (escopo 1, 2 e 3). Nesse sentido, em 2015, no Brasil, 71 foram categorizados como ouro, 58 categorias prata (inventário completo, porém não verificado) e 8 categorias bronze (inventário parcial), ilustrado na figura 2.

Cabe lembrar que o Instituto Nacional de Metrologia, Normalização e Qualidade Industrial (INMETRO) é parceiro de Programa GHG Protocol e é o responsável pela acreditação de Organismos de certificação; ou melhor, de reconhecimento das competências técnicas dos organismos de avaliação da conformidade, os quais executam certificações de produtos, sistemas de gestão, pessoas, processos ou serviços. Para tanto, utilizam-se programas de acreditação cujos requisitos devem ser atendidos plenamente pelos solicitantes.

Ressalta-se que a participação no Programa Brasileiro GHG Protocol é de caráter voluntário para qualquer organização e, da mesma forma, nenhuma delas é obrigada a ter seu inventário de GEE verificado por uma terceira parte. A esta, por sua vez, é creditada a função de oferecer aos stakeholders a confiança de que os registros de GEE, verificados ao Programa Brasileiro, representam contabilizações e informações confiáveis das emissões de GEE. Cruz (2015) destaca que o GHG Protocol é uma ferramenta de contabilidade utilizada por líderes governamentais e empresariais para entender, quantificar e gerenciar emissões de gases de efeito estufa.

\section{Responsabilidade Social Corporativa e o gerenciamento das emissões atmosféricas}

A Responsabilidade Social Corporativa (RSC) pode ser definida como um compromisso das empresas com os diferentes grupos de interesse no âmbito social, ambiental e econômico (CUESTA et al., 2003 citado por CUNHA, 2016; ALAZZANI et al., 2013 citado por CUNHA, 2016; MOSEÑE et al., 2013 citado por CUNHA, 2016; BONSÓN et al., 2015 citado por CUNHA, 2016).

Nota-se, pelos últimos anos, que a responsabilidade social começou a desempenhar um papel no posicionamento estratégico global das companhias em relação às alterações climáticas, uma vez que o componente de mercado se tornou cada vez mais importante (KOLK et al., 2005 citado por LEE, 2012). Em tal contexto, instituições com compromisso socioambiental são interpretadas como mais lucrativas, à medida que estão menos sujeitas a pagamentos de passivos ambientais, e trazem maior segurança em períodos de turbulência na economia (MARTINS et al., 2014; SILVA, 2015).

Em vista disso, no panorama mundial, o gerenciamento de riscos referentes às condições do clima passa a ser uma ferramenta de grande importância para os gestores, ainda mais quando existe essa dinâmica circunstancial de fatores de alterações climáticas ao longo do tempo (SOUSA et al., 2008). Segundo Farias et al. (2011), percebe-se que algumas corporações e investidores estão-se movendo em direção à nova economia de baixo carbono e, consequentemente, estão mais preocupadas com a medição e a avaliação das suas emissões de GEE.

Os relatórios de sustentabilidade evidenciam, de fato, informações significativas a respeito dos impactos e desempenhos econômicos, sociais, ambientais e de administração ou gestão de uma empresa. 
Além disso, demonstram a responsabilidade corporativa e valor em longo prazo, que dizer, um comportamento transparente e ético que contribui para o desenvolvimento sustentável.

Outra forma de as empresas demonstrarem seu interesse pela responsabilidade social e ambiental é através do Índice de Sustentabilidade Empresarial (ISE). Assim, este seria definido como ferramenta para análise comparativa do desempenho das companhias listadas na BM\&F Bovespa, sob o aspecto da sustentabilidade corporativa, baseada em eficiência econômica, equilíbrio ambiental, justiça social e governança corporativa.

Segundo Melo et al. (2012) estudaram 20 empresas do setor da celulose listadas na BOVESPA e, com efeito, constataram que, em 2010, as que tiveram os melhores indicadores financeiros foram justamente as que fizeram parte do (ISE). Inclusive, estudos apontam um avanço no número de organizações que informam ao público a adoção de práticas socioambientais, alinhando os conceitos de Sustentabilidade e Governança Corporativa (PEDROSO et al., 2007; MILANI FILHO, 2008).

Todavia, para que as companhias sejam sustentáveis, os gestores necessitam de ferramentas adequadas e eficazes e, nesse aspecto, as boas práticas de governança podem contribuir (JAMES-OVERHEU et al., 2009). Nota-se, portanto, que, cada vez mais, as questões ambientais são utilizadas pelas instituições através de relatórios tradicionais e/ou complementares, de forma que os stakeholders identifiquem os prejuízos ambientais causados nas atividades dessas empresas (MELO, 2016).

\section{METODOLOGIA}

A valer, o presente trabalho consiste em um estudo quantitativo e qualitativo, realizado com dados secundários, obtidos por meio de pesquisa documental, dos relatórios de emissões divulgados na base do programa GHG Protocol Brasileiro e informações nos sites institucionais das empresas selecionadas. Os dados analisados são referentes ao ciclo dos inventários de 2016, que representam informações de 2015. Os inventários presentes na base de dados são elaborados conforme metodologia estipulada no Programa Brasileiro GHG Protocol, baseada em um processo colaborativo de construção envolvendo coordenadores do Programa e as companhias.

Para o alcance dos objetivos, foram escolhidas as empresas com atuação no estado do Maranhão que participam do GHG Protocol. Logo, com esse propósito, foi consultado o banco de dados referentes a esse programa, disponível no site do Registro Público de Emissões. Dessa forma, fazem parte da pesquisa corporações dos seguintes setores: Indústria de transformação; Agricultura, pecuária, produção florestal, pesca e aquicultura; Construção; Comércio; Transporte, armazenagem e correio; Indústria extrativa. Assim, no intuito de facilitar a correlação das informações, optou-se por classificá-las conforme o quadro 1.

Como se vê, os dados secundários provenientes dos inventários das instituições pesquisadas no Maranhão foram tabulados e organizados em quadros e gráfico. Devido à pouca quantidade de empresas atuantes nesse estado que divulgam os dados anuais de emissões GEE, por meio desse tipo de listagem na plataforma do programa GHG Protocol, decidiu-se por analisar todos os seus dados existentes, referentes ao período de 2008 a 2015 
Quadro 1: Classificação das empresas de acordo com o setor de atuação no Maranhão.

\begin{tabular}{|l|c|}
\hline \multicolumn{1}{|c|}{ Setor das Empresas analisadas } & Classificação \\
\hline Industria de transformação & $\mathrm{A}$ \\
\hline Agricultura, pecuária, produção florestal, pesca e aquicultura & $\mathrm{B}$ \\
\hline Construção & $\mathrm{C}$ \\
\hline Comércio & $\mathrm{D}$ \\
\hline Transporte, armazenagem e correio & $\mathrm{E}$ \\
\hline Indústria extrativa & $\mathrm{F}$ \\
\hline Industria de transformação & $\mathrm{G}$ \\
\hline
\end{tabular}

Outro ponto do trabalho foi identificar as possíveis falhas na veracidade das informações. Nessa fase, foram analisadas as firmas que possuem seus inventários verificados de forma independente, ou seja, por agência contratada para categorizar os dados disponibilizados por essas companhias em selos classificados em ouro, prata e bronze.

Ademais, buscou-se também avaliar o nível de abrangência dos inventários na sociedade, através de uma varredura nos sites das empresas notadas por A, B, C, D, E, F e G, com o intuito de avaliar o grau de disponibilidade desses dados ao público. Para finalizar, identificaram-se ações ambientais para redução de emissões de GEE nos inventários e ou nos sites das entidades estudadas. Para tanto, adotaram-se as perguntas utilizadas pelo Programa GHG Protocol dentro dos inventários, a saber: "A organização possui projetos de redução de emissões?", "Possui descrição de estratégias e projetos para a gestão de emissões de GEE?", "A organização possui projetos de compensação de emissões?". Dessa maneira, os dados foram coletados, tabulados e, posteriormente, apresentados em quadros.

\section{RESULTADOS E DISCUSSÃO}

Conforme o descrito antes, os inventários possuem suas categorias de verificação definidas em ouro, prata e bronze. Cabe destaque a categoria ouro, por ser considerada a mais completa. Sendo assim, ela precisa ser verificada por um Organismo Verificador (pessoa(s) competente(s) e independente(s), com a responsabilidade de conduzir e relatar processos de verificação), e esse organismo precisa ser acreditado segundo os critérios do INMETRO.

Um dos parâmetros de avaliação dos dados reportados pelas empresas junto ao GHG Protocol são as categorias de verificação. De acordo com os dados analisados, observou-se que, ao longo do período de realização desta pesquisa, 2008 a 2015, os inventários das empresas, compreendidas no estudo, estão distribuídos nas respectivas classes de forma bem distinta. Assim, identificou-se que as sete organizações que já declararam seus inventários no GHG Protocol possuem 21 categorias ouro, 16 pratas e 0 bronzes (Gráfico 1). A empresa F, integrante do programa desde 2009, possui o maior número de classificação com selo ouro. Vale ressaltar que as distinções para verificação levam em consideração à quantidade de informação disponibilizada nos inventários, e os selos precisam ser renovados a cada novo arrolamento realizado.

É possível perceber, no gráfico, que não foram declarados inventários na categoria bronze (inventário incompleto). Considera-se, desse modo, que o número relacionado como sendo ouro demonstra um comprometimento das empresas com o programa e com a gestão das emissões, pois buscam uma 
transparência em seus dados. Um aspecto questionável no gráfico é o caso das instituições que permanecem na categoria prata (B, C e G) e não buscam evoluir para o selo ouro, ficando a dúvida quanto ao seu nível de interesse em obter melhoria constante nos reportes ou se tal situação pode ser justificada por custos das verificações.

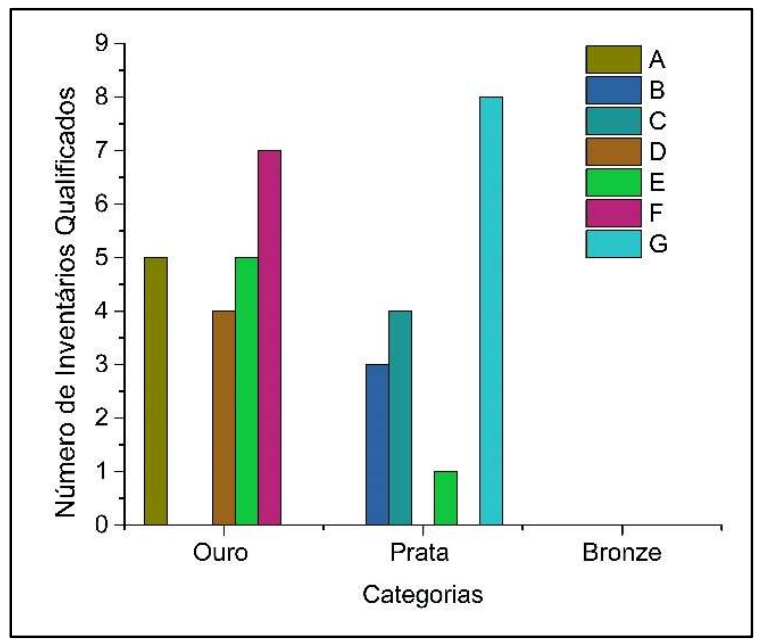

Gráfico 1: Número de Inventários por qualificação no Maranhão.

Outrossim, o Programa GHG Protocol não possui uma ferramenta para analisar a transparência e grau de certeza dos dados informados, por isso, a categoria que reconhece o selo ouro aos inventários é uma das formas de gerar um nível aceitável de confiabilidade das informações. De acordo com Ogle et al. (2013), um inventário nacional robusto cria uma forte relação entre os dados de emissão de GEE, o planejamento e implementação de políticas correlatas. Por sua vez, tal fato provê a oportunidade do desenvolvimento de um banco de dados de emissão confiável a partir do monitoramento de tendências com a divulgação dos resultados de mitigação.

A disponibilidade de tais listas de emissões nos sites das empresas é uma forma de tornar o reporte das emissões mais acessível e disseminar as boas práticas para os usuários. No quadro 2, percebe-se que a companhia B foi a que melhor evidenciou sua iniciativa e disponibiliza o endereço de acesso ao site do GHG Protocol, onde está localizado o seu rol de informações. As corporações F e G divulgam a iniciativa, porém não disponibilizam um link de acesso a essas listagens. Por sua vez, as organizações A, C, D e E não possuem informações que direcione o público interessado a ter conhecimento de suas práticas.

Quadro 2: Localização do inventário ou informações no site institucional.

\begin{tabular}{|c|l|}
\hline Empresa & \multicolumn{1}{c|}{ Localização do Inventário de Emissões } \\
\hline A & Não disponibiliza o relatório no site da empresa \\
\hline B & Divulga sua participação no site e disponibiliza em sua página um link para o programa \\
\hline C & Não disponibiliza o relatório no site da empresa \\
\hline D & Não disponibiliza o relatório no site da empresa \\
\hline E & Não disponibiliza o relatório no site da empresa \\
\hline F & Divulga sua participação, porém não disponibiliza o inventário nem o link do programa \\
\hline G & Divulga sua participação, porém não disponibiliza o inventário nem o link do programa \\
\hline
\end{tabular}

Dos dados apresentados no quadro 2, nota-se que, no Maranhão, as poucas empresas que fazem parte do programa não divulgam sua boa prática nos sites, que poderiam ser o cartão de visita para a sociedade e seus stakeholders. Observa-se, portanto, que a divulgação no programa ainda é muito discreta, 
transparecendo uma preferência por parte das companhias em manter o reporte de inventário somente para cumprimento de protocolos internos. Contudo, é essencial que estes sejam amplamente divulgados num âmbito público para, assim, torná-los uma ferramenta atraente para a sociedade e um banco de dados utilizável.

Nesse sentido, para Sousa Filho et al. (2007), a comunicação entre corporações e consumidores ficou mais fácil, concreta e rápida com a Internet, sendo esta uma excelente ferramenta para a comunicação de informações relacionadas à Responsabilidade Social das Empresas (SER). Como se vê, em consonância com os autores supracitados, uma possibilidade de os inventários tornarem-se um banco de informações mais acessível no Maranhão, seria a sua divulgação em sites públicos tais como, o Portal do Estado, a Secretaria de Meio Ambiente do Estado e Município, entre outros. Realizar esse tipo de exposição é de basilar importância, pois, leva transparência para a sociedade e conscientiza as pessoas sobre a seriedade desses informes na gestão das emissões e controle das mudanças climáticas.

Exemplo disso é o que realiza o estado de São Paulo, uma vez que divulga publicamente o Registro Público de Emissões de Gases de Efeito Estufa, instituído e regulamentado pela Política Estadual de Mudanças Climáticas (PEMC - Lei Estadual no 13.798/2009). Ao instaurar tal regulamentação, é possível estabelecer critérios mensuráveis e acompanhar, de forma transparente, o resultado de medidas de mitigação e absorção de gases de efeito estufa, bem como auxiliar os agentes privados e públicos na definição de estratégias para o aumento de eficiência e produtividade (SÃO PAULO, 2009). Em contrapartida, no que se refere às ações para redução de gases de GEE das empresas observadas no estudo, o quadro 3 apresenta um resumo das informações presentes nos arrolamentos avaliados.

Quadro 3: Resumo das informações ambientais das empresas presentes no MA relatadas no inventário.

\begin{tabular}{|c|c|c|c|}
\hline Empresas & $\begin{array}{c}\text { A organização possui projetos } \\
\text { de redução de emissões? }\end{array}$ & $\begin{array}{c}\text { Possui descrição de estratégias e } \\
\text { projetos para a gestão de emissões de } \\
\text { GEE? }\end{array}$ & $\begin{array}{c}\text { A organização possui projetos de } \\
\text { compensação de emissões? }\end{array}$ \\
\hline A & Não relatado & Não relatado & Não relatado \\
\hline B & Não relatado & Sim & Não relatado \\
\hline C & Não relatado & Não relatado & Não relatado \\
\hline D & Não relatado & Sim & Não relatado \\
\hline E & Não relatado & Não relatado & Não relatado \\
\hline F & Sim & Sim & Não relatado \\
\hline$G$ & Não relatado & Sim & \\
\hline
\end{tabular}

Nota-se, nas informações do quadro 3 , que as empresas $D$ e $F$ foram as que mais forneceram informações ambientais no reporte dos dados. Ainda na imagem acima, é possível perceber que a empresa G, por sua vez, realiza algumas estratégias e projetos de redução de gases de GEE e, além disso, a empresa tem realizado investimentos e implementado diversas ações que se refletem em redução de emissões de GEE, tais como: implantação do novo digestor na unidade $G$, que permitiu a redução de $33,5 \%$ no consumo de gás natural, representando uma redução de 115 mil ton $\mathrm{CO}_{2}$ e no balanço de emissões; nova caldeira de biomassa na unidade $X$, que também permitiu a redução de $11,2 \%$ no consumo de gás natural, representando uma redução de 18 mil t $\mathrm{CO}_{2} \mathrm{e}$ no balanço de emissões.

Em continuidade às ações propostas, tem-se o Programa de Eficiência Operacional, que foi responsável, dentre outros ganhos, pela queda no consumo em $41,0 \%$ de energia elétrica em todas as 
unidades e pela consequente redução de 53 mil ton $\mathrm{CO}_{2}$ de escopo 2 . Além disso, a autogerarão de energia elétrica nas unidades $X$ e $Y$, bem como a exportação de energia elétrica para a rede, evitaram juntas a emissão de 570 mil ton $\mathrm{CO}_{2}$ e para a atmosfera ${ }^{2}$.

Ademais, comparando os informes ambientais apresentadas nos relatórios de emissões do registro público com as informações de projetos para redução de emissões nos sites das empresas, verifica-se que não há uniformidade dos relatos. E esses resultados obtidos são condizentes com os estudos de Costa e Marion (2007), que apontam para uma falta de comprometimento por parte das companhias em demonstrar as suas informações ambientais em relatórios que facilitem a análise dos usuários.

No caso da organização A, representada pela unidade no Maranhão, neste estudo, não apresentou informação alguma dos seus projetos de redução de gases de efeito estufa nos inventários. Porém, em sua página na internet, há um relatório de sustentabilidade e documento do Fórum Clima IE (2010), os quais relatam algumas ações nessa área. Como exemplo desses informes, têm-se que:

Em 2010, a empresa A lançou oficialmente seu Programa de Eficiência Energética para a América Latina e Caribe, cujas principais atividades estão relacionadas à otimização de processos, redefinição de matriz energética por meio da busca de substituição de combustíveis por insumos com menores fatores de emissão e adoção de tecnologias mais eficientes $O$ programa é voltado também para a conscientização e o engajamento de todos os colaboradores da empresa, tanto em relação à questão energética dos processos industriais da companhia, quanto ao uso doméstico consciente. (IE, 2010)

Outro destaque é a empresa F, que não referenciou projeto algum de compensação nos inventários, porém anunciou em sua página, como forma de compensação, um plano de metas para reduzir as emissões até 2020 . Entre as medidas de mitigação está a redução de $74 \%$ da queima de gás metano em minas de carvão e troca de óleo combustível por gás natural em suas unidades (CHIARETTI et al., 2016).

Clarkson et al. (2011) procurou compreender a ligação entre o relato e o desempenho ambiental corporativo de 51 empresas dos setores de mina e manufatura da Austrália, concluindo que existe uma relação positiva entre o desempenho e o relato ambiental. Burnett et al. (2008) também examinou o vínculo entre o desempenho ambiental e a eficiência produtiva de uma indústria de eletricidade dos Estados Unidos. Os resultados demonstraram que uma gestão ambiental proativa permite reduzir seus custos e pode contribuir para a adoção de um sistema de gestão de gastos.

Farias (2013) discorre que a elaboração do inventário de emissões de GEE tende a gerar impacto nos desempenhos operacional e financeiro das organizações empresariais. Segundo Farias (2013), a comunicação do inventário e as ações de redução de GEE têm a capacidade de produzir resultados por meio de ganhos intangíveis, do acesso a fontes diferenciadas de capital, da vantagem competitiva sustentável e do atendimento aos anseios dos stakeholders.

No entanto, complementando a problemática, Winn et al. (2011) afirma que, mesmo quando as organizações buscam reduzir suas emissões, elas não concretizam, de fato, ações para mitigação/adaptação, tampouco percebem os riscos climáticos que podem enfrentar. Pizer et al. (2015) destaca a importância da adoção de estratégias de mitigação e a possibilidade de comparação da efetividade das mesmas por meio de

\footnotetext{
${ }^{2}$ Inventário de emissões de gases de efeito estufa.
} 
métricas padrões, que são de fundamental importância para a participação da sociedade civil, demonstrando transparência e facilitando as análises.

Nesse sentido, as iniciativas das organizações somente poderão ser efetivas se forem fundamentadas no conhecimento de suas próprias emissões para que, desse modo, elas sejam reduzidas. Sendo assim, considera-se, neste trabalho, que a melhor expressão para as emissões é a realização de um inventário bem elaborado e abrangente em todos os setores das organizações.

\section{CONSIDERAÇÕES FINAIS}

O Maranhão possui um retrato das emissões abaixo da realidade. Em outras palavras, o número de empresas presentes no estado que fazem parte do programa de inventários é muito pequeno, o que torna a ferramenta de divulgação desses dados pouco representativa. Assim sendo, no que se refere ao nível de abrangência dos inventários no Maranhão, é indispensável que haja uma maior divulgação do Programa de declaração de GEE, pois, na maioria das vezes, poucos tomam conhecimento da grandeza do programa como ferramenta de gestão das emissões.

Quanto à veracidade das informações, nota-se que a maioria das empresas observadas possui seus róis com categoria ouro. Todavia, apesar de os dados despertarem muitos questionamentos, essa é a única forma que o programa tem de atribuir transparência a tais informações, haja vista que elas são verificadas por organismos acreditados pelo INMETRO.

No que se refere às boas práticas e detalhamento dos arrolamentos, percebe-se, naqueles analisados no presente trabalho, que há uma carência na exposição das informações. Isso porque, uma vez que o programa em análise deixa aberta a possibilidade da escolha do nível de inserção dos dados, algumas empresas não primam em minuciar seus inventários. Entende-se, contudo, que esse tipo de registro de emissões de gases de GEE, se bem feito, pode representar uma excelente oportunidade para revisar procedimentos de medida de insumos, produtos e subprodutos.

Dessa forma, como contribuição de ordem prática, é possível sugerirmos algumas recomendações em aspectos, tais como: procedimento de coleta de dados, robustez dos dados, justificativas de alteração de escopo, análise crítica dos dados apresentados e informações de projetos para redução das emissões. Desta feita, para a elaboração efetiva dos inventários é necessária à complementação de alguns pontos, a saber: declarar o inventário contendo os escopos 1, 2 e 3; apresentar todos os poluentes gerados nos processos pertencentes aos 6 gases do Protocolo de Kyoto; apresentar no inventário um fluxograma de onde são geradas as informações que foram declaradas pela empresa; estabelecer um plano de gestão da qualidade para os inventários.

Além desses, elaborar uma política de recálculo do ano base sempre que os processos que geraram as informações sofrerem alguma mudança; análise crítica dos dados inventariados; divulgação para os funcionários das empresas participantes; formalizar os inventários para a sociedade; criar metas de redução das emissões; realizar verificação externa; traçar ações em decorrência dos dados de emissões apresentados; e treinar equipe para elaboração de inventários. 
Assim concluído, é possível afirmar que, na forma como são erigidos na atualidade, os inventários não conseguem cumprir seu papel no gerenciamento das emissões atmosféricas, pois não possuem metas e ações para reduzir os lançamentos de GEE, tornando-se apenas uma ferramenta de marketing ambiental para valorar os serviços das empresas.

De tal modo, é importante que seja permitida a comparabilidade entre as emissões de diferentes empresas e que se ajude a promover a cooperação entre elas, e, assim, consequentemente, estabelecer uma plataforma de dados capaz de associar experiências, otimizar a eficácia e interoperabilidade da ferramenta, testar diferentes abordagens e promover o intercâmbio das melhores práticas em ações de mitigação e adaptação às mudanças climáticas. Em relação às pesquisas futuras, seria interessante buscar um diagnóstico no panorama nacional, a fim de visualizar como a ferramenta está sendo implementada nas corporações, com o objetivo de analisar as ações efetivadas na gestão das emissões atmosféricas.

\section{REFERÊNCIAS}

BARBIERI, C.. Gestão Ambiental Empresarial. São Paulo: Saraiva, 2016.

BRASIL. Lei n.12187 de 29 de dezembro de 2009. Institui a Política Nacional sobre Mudança do Clima (PNMC) e dá outras providências. Brasília: DOU, 2009.

BRASIL. Ministério da Ciência e Tecnologia. Comunicação Nacional Inicial do Brasil à Convenção-Quadro Das Nações Unidas sobre mudança no clima. Brasília: MCT, 2004.

BRASIL. Ministério da Ciência e Tecnologia. Estimativas Anuais de Emissões de Gases de Efeito Estufa no Brasil. 3 ed. Brasília: MCT, 2016a.

BRASIL. Ministério de Ciência e Tecnologia. Segunda comunicação nacional do Brasil à Convenção-Quadro das Nações Unidas sobre mudança do clima. Brasília: MCT, 2010.

BRASIL. Ministério de Ciência e Tecnologia. Terceira comunicação nacional do Brasil à Convenção-Quadro das Nações Unidas sobre mudança do clima: sumário executivo. Brasília: MCT, 2016b.

BURNETT, R.; HANSEN, D.. Ecoefficiency: defining a role for environmental cost management. Accounting, Organizations and Society, v.33, p.551-581, 2008. DOI: https://doi.org/10.1016/i.aos.2007.06.002

CHIARETTI, D.; MÁXIMO, L.. Cresce grupo de empresas que reportam emissões. GHG Protocol Brasil, São Paulo, 2016.

CLARKSON, P.; OVERELL, M.; CHAPPLE, L.. Environmental reporting and its relation to corporate environmental performance. Abacus, v.47, n.1, p.27-60, 2011. DOI: https://doi.org/10.1111/i.1467-6281.2011.00330.x

COP-21. Conferência das Nações Unidas sobre as Mudanças Climáticas de 2015. Acordo da COP-21: Convención Marco de las Naciones Unidas sobre el Cambio Climático. Le Bourget: COP-21, 2015.
COP-22. Conferência das Nações Unidas sobre as Mudanças Climáticas de 2016. Acordo da COP-22: Convención Marco de las Naciones Unidas sobre el Cambio Climático. Marrakesh: COP-22, 2015.

COP-23. Conferência das Nações Unidas sobre as Mudanças Climáticas de 2017. Acordo da COP-23: Convención Marco de las Naciones Unidas sobre el Cambio Climático. Bonn: COP-23, 2015.

COSTA, R. S.; MARION, J. C.. A uniformidade na evidenciação das informações ambientais. Revista Contabilidade e Finanças, São Paulo, n.43, p.20-33, 2007.

CRUZ, T. S.. Evidenciação de informações de enfrentamento às mudanças climáticas e desempenho econômicofinanceiro: um estudo com as empresas listadas no ISE da BM\&FBovespa. Dissertação (Mestrado em Ciências Contábeis) -Universidade Federal da Bahia, Salvador, 2015.

CUNHA, D. R.. Factores de divulgación de la información medioambiental en el sector petrolero mundial. Tese (Doutorado em Contabilidade) - Universidad Saragoça, Saragoça, 2016.

FARIAS, L. G. Q.. Estratégias de legitimidade de Suchman evidenciadas pelas empresas brasileiras destinatárias do pedido do Carbon Disclosure Project. Tese (Doutorado em Administração) - Universidade Federal da Bahia, Salvador, 2013.

FARIAS, L. G. Q.; ANDRADE, J. C. S.; GÓES, M. F. B.; RABÊLO FILHO, R. L. N.. Carbon Disclosure Project (CDP): Caracterização da Evidenciação de Informações Ambientais das Empresas Brasileiras entre 2006 e 2010. Sistemas \& Gestão, v.6, n.4, p.431-446, 2011.

FGV. Fundação Getúlio Vargas. Guia para elaboração de relatórios corporativos de emissões de gases de efeito estufa (GEE). Rio de Janeiro: FGV, 2009.

FGV. Fundação Getúlio Vargas. Registro Público de Emissões: Inventários por qualificação. São Paulo: FGV, 2016. 
FGV. Fundação Getúlio Vargas. Registro Público de Emissões: Membros do Programa Brasileiro GHG Protocol. São Paulo: FGV, 2017.

IE. Instituto Ethos. Fórum Clima: carta aberta ao Brasil sobre mudanças climáticas. São Paulo: IE, 2010.

IE. Instituto Ethos. Fórum Clima: o desafio de harmonização das políticas estaduais de mudanças climáticas. São Paulo: IE, 2012.

JAMES-OVERHEU, C.; COTTER, J.. Corporate governance, sustainability and the assessment of default risk. Asian Journal of Finance \& Accounting, v.1, n.1, p.34-53, 2009. DOI: https://doi.org/10.5296/ajfa.v1i1.93

LEE, S. Y.. Corporate carbon strategies in responding to climate change. Business Strategy and the Environment, v.21, n.1, p.33-48, 2012. DOI:

https://doi.org/10.1002/bse.711

MARTINS, M. R. S.; SILVA, J. G. F.. O sistema de gestão ambiental baseado na ISO 14000: Importância do instrumento no caminho da sustentabilidade ambiental. 103 Revista Eletrônica em Gestão: Educação e Tecnologia Ambiental, Santa Maria, p.1460-1466, 2014.

MELO, E. C.; ALMEIDA, F. M.; SANTANA, G. A. S.. Índice de sustentabilidade empresarial (ISE) e desempenho financeiro das empresas do setor de papel e celulose. Revista de Contabilidade e Controladoria, Curitiba, v.4, n.3, p.95-112, 2012.

MELO, H. D.; MELO, J. F. M.; PEREIRA, A. W. R.; BARBOSA, M. F. N.. Análise da frequência dos itens ambientais nos instrumentos de evidenciação voluntária e obrigatória: estudo de caso nas empresas do segmento de siderurgia registradas na Bovespa entre o período de 2008 a 2012. Revista Metropolitana de Sustentabilidade, São Paulo, v.6, n.1, p.24-42, 2016.

MILANI FILHO, M. A. F.. Responsabilidade social e investimento social privado: entre o discurso e a evidenciação. Revista Contabilidade \& Finanças, São Paulo, v.19, n.47, p.89-101, 2008.

MINAS GERAIS. Decreto $\mathbf{n} \mathbf{4 5 2 2 9}$ de $\mathbf{0 3}$ de dezembro de 2009. Regulamenta medidas do Poder Público do Estado de
Minas Gerais referentes ao combate às Mudanças Climáticas e Gestão de Emissões de Gases de Efeito Estufa. Belo Horizonte: DOE, 2009.

OGLE, M. S. P.; OLANDER, L.; WOLLENBERG, L.; ROSENSTOCK, T.; TUBIELLO, F.; PAUSTIAN, K.; BUENDIA, L.; NIHART, A.; SMITH, P.. Reducing Greenhouse Gas Emissions and Adapting Agricultural Management for Climate Change in Developing Countries: Providing the Basis for Action. Hoboken: John Wiley \& Sons, 2013. DOI: https://doi.org/10.1111/gcb.12361

PEDROSO, M. C.; ZWICKER, R.. Sustentabilidade na cadeia reversa de suprimentos: um estudo de caso do projeto plasma. Revista de Administração da USP, São Paulo, v.42, n.4, p.414-430, 2007.

PIZER, W.; ALDY, J.; AKIMOTO, K.. Comparing emissions Mitigation Efforts across countries. Cambridge: Harvard, 2015. DOI: http://doi.org/10.2139/ssrn.2697250

RIO DE JANEIRO. Lei $\mathbf{n} \mathbf{. 5 6 9 0}$ de $\mathbf{1 4}$ de abril de 2010. Institui a política estadual sobre mudança global do clima e desenvolvimento sustentável e dá outras providências. Rio de Janeiro: DOE, 2010.

SÃO PAULO. Lei n.13798 de 09 de novembro de 2009. Institui a Política Estadual de Mudanças Climáticas (PEMC). São Paulo: DOE, 2009.

SILVA, E. H. D. R.. Análise comparativa de rentabilidade: um estudo sobre o Índice de Sustentabilidade Empresarial. Gestão \& Produção, São Carlos, v.22, n.4, p.743-754, 2015.

SOUSA FILHO, J. M.; WANDERLEY, L. S. O.. Divulgação da responsabilidade social empresarial: como os websites empresariais vêm sendo utilizados por empresa de energia e varejo. Cadernos EBAPE.BR, Rio de Janeiro, v.5, n.2, 2007.

SOUSA, R.; VOSS, C. A.. Contingency research in operations management practices. Journal of Operations Management, v.26, n.6, p.697-713, 2008. DOI:

https://doi.org/10.1016/j.jom.2008.06.001

WINN, M.. Impacts from climate change on organizations: a conceptual foundation. Business Strategy and the Environment, v.20, n.3, p.157-173, 2011. DOI: https://doi.org/10.1002/bse.679

A CBPC - Companhia Brasileira de Produção Científica (CNPJ: 11.221.422/0001-03) detém os direitos materiais desta publicação. Os direitos referem-se à publicação do trabalho em qualquer parte do mundo, incluindo os direitos às renovações, expansões e disseminações da contribuição, bem como outros direitos subsidiários. Todos os trabalhos publicados eletronicamente poderão posteriormente ser publicados em coletâneas impressas sob coordenação da Sustenere Publishing, da Companhia Brasileira de Produção Científica e seus parceiros autorizados. Os (as) autores (as) preservam os direitos autorais, mas não têm permissão para a publicação da contribuição em outro meio, impresso ou digital, em português ou em tradução. 